\title{
BUDAYA KREATIF DALAM KONSEP DAN PENGEMBANGAN
}

\author{
Eko Susanto $^{1}$
}

\begin{abstract}
This study is an attempt to understand the concept of culture as a creative and cultural influence of external factors in fostering creativity. Culture is believed to be one of the aspects that can facilitate the growth of individual creativity. Creative culture as behavior, activity or way of life of a person or group of people embedded within it an element of novelty to life effective, communicative and refer to attitudes toward the social situation and the phenomenon of life. This study attempted to reveal the dominance of internal and external forces that encourage individual creativity. Of the 198 participants were high school students known that the external aspect dominates $63 \%$ as the force that drives one's creativity. Socializing creative culture from an early age is expected to facilitate the growth of creativity in the individual.
\end{abstract}

Keywords: Creative Culture, Creativity, Social Situation, Phenomenon of Life.

\section{JOMSIGN: Journal of Multicultural Studies in Guidance and Counseling}

Website : http://ejournal.upi.edu/index.php/JOMSIGN

Permalink: http://ejournal.upi.edu/index.php/JOMSIGN/article/view/8287

How to cite (APA): Susanto, E. (2017). Budaya kreatif dalam konsep dan pengembangan. JOMSIGN: Journal of Multicultural Studies in Guidance and Counseling, 1(2), 191-200.

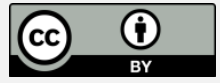

This is an open access article distributed under the terms of the Creative Commons Attribution 4.0 International License, which permits unrestricted use, distribution, and reproduction in any medium, provided the original work is properly cited.

\section{PENDAHULUAN}

Kreativitas dapat dianggap sebagai kapasitas yang melekat dan kebutuhan dari spesies manusia yang memiliki nilai kelangsungan hidup bagi individu maupun budaya (Runco \& Albert, 1990). Ditegaskan pula bahwa kreativitas adalah bagian dari budaya sebagai perubahan genetik yang dihasilkan dari evolusi biologis (Csikszentmihalyi, 1996). Dalam evolusi biologis variasi yang acak berlangsung pada gen dan kromosom, sedangkan pada perubahan evolusi budaya berlangsung di meme, yaitu dalam satuan informasi yang dibuat, dipelihara dan ditransmisikan oleh budaya. Bahasa, perkakas, ukiran, lukisan, norma-norma sosial, nilai-nilai dan ide-ide seperti kasih sayang, kebebasan, berbakti, antara lain, contoh meme yang diwariskan secara turun temurun.

\footnotetext{
${ }^{1}$ Universitas Muhammadiyah Metro, Indonesia; ekobkummetro@gmail.com.
} 
Memes, sebagai hasil dari evolusi budaya, tidak bisa secara otomatis diteruskan pada generasi berikutnya. Setiap orang harus belajar dari awal demi kelangsungan hidup dan pelestarian budaya. Namun demikian untuk kelangsungan hidup seseorang mungkin harus berani mengubah meme tersebut. Upaya untuk mengubah meme yang ada dapat diidentifikasi sebagai sebuah usaha kreatif. Misalnya tata cara bertani tradisional yang mengharapkan air dari turunnya hujan, diubah dengan membuat ledeng yang dapat mengaliri sawah setiap saat, serta banyak contoh lain dalam kehidupan di masyarakat. Kreativitas akan bermakna dan berguna jika ide atau produk yang dihasilkan mengakomodir keinginan banyak orang dan diadopsi oleh orang lain. Dengan demikian dapat dipahami kreativitas sebagai proses mental yang tidak dapat dipisahkan dari sistem sosial-budaya yang terdapat fungsi individu di dalamnya. Sistem ini dapat memfasilitasi atau menghambat perubahan meme juga sebagai pengaruh penilaian tentang produk kreatif atau ide kreatif. Kreativitas harus dianggap sebagai fenomena budaya dan sosial bukan hanya sekedar proses mental (Csikszentmihalyi, 1999).

Ketertarikan pada lingkungan sosial-budaya dan sejarah kreativitas dikembangkan pada tahun 1980-an dan mendapatkan momentum pada tahun 1990-an (Barron, 1988; Csikszentmihalyi, 1988, 1990, 1996, 1999; Lubart \& Sternberg, 1988, 1995; Simonton, 1988, 1991, 1996; Sternberg \& Lubart, 1991. 1992; Ludwig, 1992). Meskipun pada tahun 1960-an dan 1970-an peneliti kreativitas mengakui bahwa praktik-praktik budaya mempengaruhi perkembangan dan ekspresi kreativitas, umumnya banyak yang meremehkan pengaruh ini. Akibatnya, banyak yang memusatkan perhatian pada kontribusi pengembangan kreativitas pada ranah kognitif dan karakteristik pribadi, seperti motivasi, kepribadian, nilai-nilai, penemuan dan pemecahan masalah.

\section{Perspektif Budaya dan Kreativitas}

Dalam perspektif peneliti Person-Centred yang pada umumnya adalah psikolog lebih memandang kreativitas dalam domain individu, dengan demikian mereka banyak mengadopsi perspektif individualistik (Montuori \& Purser, 1995; Simonton, 2000). Perspektif sistem yang dinamis perlu dipertimbangkan dalam studi kreativitas, hal ini untuk meyakinkan pembaca dengan tidak mengabaikan dukungan psikologi pada pendekatan sosiologi (Csikszentmihalyi, 1999). Lingkungan sosial-budaya juga menjadi ukuran dari produk kreativitas yang dihasilkan. Csikszentmihalyi (1988, 1999) lebih lanjut menjelaskan bahwa kreativitas adalah proses yang dihasilkan dari interaksi antara tiga kekuatan 
utama, (1)budaya, yang menyimpan dan mengantarkan ide-ide, nilai-nilai dan keyakinan pada generasi berikutnya; (2) sistem sosial, yang mengandung unsur perilaku, nilai-nilai dan informasi (meme) yang akan dilestarikan; (3) individu, sebagai unit yang membawa transformasi ke dalam domain sosial dan budaya. Disadari bahwa kreativitas adalah produk dari interaksi individu, sistem sosial dan budaya, yang muncul sebagai fenomena kompleks tidak sekedar yang digambarkan dalam perspektif individualistik.

Pembahasan tentang budaya terkait erat dengan berbagai variable sosial dan keragaman. Sikap bijak untuk tidak menyederhanakan konsep budaya dalam kehidupan masyarakat. Dalam perspektif tertentu budaya dapat dimaknai sebagai cara hidup seseorang atau sekelompok orang (McLeod, 2013: 287-288). Budaya dapat dipahami sebagai pola makna yang tertanam dalam simbol dan diwariskan secara historis, sebagai sebuah sistem konsepsi turunan yang diekspresikan dalam bentuk simbolik dan digunakan untuk berkomunikasi, bertahan hidup, dan mengembangkan pengetahuan tentang hidup dan sikap terhadap kehidupan (Clifford Geertz dalam McLeod, 2013). Lebih lanjut ditegaskan budaya merupakan gabungan dari semua tradisi dan nilai-nilai, keyakinan, perilaku, kebiasaan dan aturan serta kekuatan ekonomi, politik dan teknologi yang beroperasi pada suatu kelompok tertentu pada waktu tertentu dalam suatu tempat tertentu (Ludwig, 1992).

Masyarakat berperan penting dalam mendorong munculnya kreativitas. Sebagai salah satu faktor eksternal yang fundamental mempengaruhi kreativitas adalah pendidikan dan pembelajaran. Pendidikan dan pembelajaran memainkan peran mendasar dalam membentuk lingkungan yang kreatif. Budaya memiliki kemampuan untuk merangsang imajinasi dan kreativitas masyarakat sekolah. Kreativitas dalam pembelajaran diwujudkan dengan membina fleksibilitas, keterbukaan untuk sesuatu yang baru, kemampuan untuk beradaptasi, dan keberanian menghadapi resiko. Imajinasi, berpikir divergen dan intuisi perlu dipertimbangkan sebagai karakteristik penting dari pendidikan di sekolah, universitas dan penyelenggara pendidikan lainnya (A. Cropley \& Cropley, 2011; A. J. Cropley, 1997; Directorate-General for Education and Culture, 2009).

\section{Aktivitas Budaya dan Pengembangan Kreativitas}

Salah satu asumsi dasar yang dalam studi ini adalah pengembangan kreativitas dalam budaya yang berbeda dan bervariasi dalam praktik mengasuh anak yang kental dengan nilai-nilai budaya, keyakinan, ekonomi dan lingkungan tertentu 
akan mempengaruhi tingkat kreativitas. Jika semua aspek ini membatasi kebebasan internal anak, maka dapat menghambat pengembangan kreativitas mereka (Stein, 1953; Gardner, 1989; Ho, 1994; Lubart, 1999).

Karakteristik antar budaya yang berbeda terhadap nilai-nilai kelompok yang dianut seperti (1) kolektivisme atau individualisme, (2) kesesuaian dengan tradisi atau kebaruan dan orisinalitas, (3) organisasi hierarkis atau egalitarianisme, (4) kontrol diri atau ekspresi diri, (5) tatanan sosial dan harmonisasi atau terbuka dan demokratis dalam penyampaian ide, (6) belajar melalui menghafal atau melalui trial and error. Walaupun budaya atau masyarakat bukan sebuah badan hukum yang homogen, namun budaya Barat sering dikaitkan dengan prinsip-prinsip individualisme liberal, demokrasi, kebebasan ekspresi diri dan cita-cita kesetaraan. Sedangkan masyarakat Timur terkait dengan budidaya kolektivisme, kesesuaian, tradisi, ketergantungan, harmoni sosial, dan ketertiban sosial, serta kontrol diri dan emosional (Rudowicz et al, 1994; Khaleefa et al, 1996; Ng, 2003).

Masyarakat kolektif dari Timur, seperti Cina, Jepang atau Afro-Arab Islam, menjunjung tinggi pada ketaatan, tugas, kerjasama, kompromi dan pengorbanan untuk kelompok. Akibatnya, orang-orang di masyarakat ini akan cenderung untuk menyesuaikan diri dalam kelompok mereka dan akan peduli dengan harmonisasi sosial sampai mengabaikan ekspresi perasaan, pendapat atau keinginan mereka sendiri. Mereka akan percaya pada pentingnya tatanan sosial dan kaku akan menegakkan aturan-aturan sosial dan norma. Mereka akan menekankan kepentingan kelompok di atas keprihatinan individu, sensitivitas stres kepada orang lain dan mendorong kontrol diri dalam menetapkan dan mencapai tujuan. Mereka juga lebih rentan untuk mengalami emosi seperti rasa malu saat berinteraksi dengan orang lain. Oleh karena itu, secara tidak langsung mereka akan lebih berhati-hati (Rudowicz et al, 1994; Farver et al, 2000; Ng, 2001).

Dalam kajian ini akan fokus pada pengaruh budaya sebagai faktor pendorong budaya kreatif individu. Untuk kepentingan tujuan kajian ini maka disusun beberapa terminologi untuk menyamakan pemahaman.

Pertama, budaya dapat dipahami sebagai pola makna yang tertanam dalam simbol dan diwariskan secara historis, sebagai sebuah sistem konsepsi turunan yang diekspresikan dalam bentuk simbolik dan digunakan untuk berkomunikasi, bertahan hidup, dan mengembangkan pengetahuan tentang hidup dan sikap terhadap kehidupan (Clifford Geertz dalam McLeod, 2013). 
Kedua, kreativitas merupakan kapasitas untuk memproduksi sesuatu yang baru dan berguna, bisa dalam bentuk ide, perilaku atau produk. Kreativitas itu hadir dengan didukung oleh faktor personal, situasional dan budaya (Runco, 2004).

Ketiga, budaya kreatif adalah perilaku, aktivitas atau cara hidup seseorang atau sekelompok orang yang melekat di dalamnya unsur kebaruan untuk kehidupan yang efektif, komunikatif dan merujuk pada sikap terhadap situasi sosial danfenomena kehidupan.

Keempat, angket budaya kreatif adalah angket yang dapat digunakan mengidentifikasi faktor pendorong unsur-unsur kreatif dalam diri individu. Faktor mana yang lebih dominan faktor individual atau faktor sosial-budaya mereka. Angket budaya kreatif dikembangkan dengan analisis faktor yang diadaptasi dari angket pribadi kreatif yang dikembangkan oleh Eko Susanto et al (2016).

Kajian ini berkontribusi dengan kebaruan fokus pada pengukuran faktor dominan internal atau eksternal yang mempengaruhi ekspresi kreatif individu dalam lingkungan budaya di Indonesia. Keterbatasan metodologi dan kesulitan yang dihadapi dalam studi budaya kreatif juga akan dibahas secara singkat pada kajian ini dan saran arah studi lanjut yang dapat dilakukan ke depan. Selain terminologi dalam kajian ini memperhatikan beberapa asumsi: 1) Setiap orang memiliki potensi kreatif namun berbeda dalam level, intensitas dan ekspresi penyaluran; 2) Kreativitas seseorang dapat berkembang jika didukung oleh lingkungan, sosial budaya yang memberi ruang untuk berkembang; 3) Pengukuran budaya kreatif bukan mengukur tinggi-rendah kreativitas seseorang tetapi untuk mengetahui aspek dominan yang menentukan kreativitas seseorang; 4) Budaya memberi pengaruh signifikan pada kreativitas seseorang. Dampaknya dapat berbeda pada setiap orang, tergantung dari budaya dimana seseorang tinggal.

\section{METODE}

Dalam kajian ini fokus pada identifikasi budaya kreatif sebagai dorongan untuk berubah ke arah yang lebih baik. Kajian dilakukan dalam tiga tahap kegiatan, (1) kajian konsep budaya kreatif sebagai dasar pengembangan angket penelitian, (2) pengembangan angket budaya kreatif, (3) analisis dan interpretasi hasil pengukuran. Kajian konsep dilakukan dengan mengidentifikasi definisi kreativitas dan budaya, kemudian membangun definisi operasional budaya 
kreatif. Definisi yang dibuat dijadikan acuan dalam pengembangan angket budaya kreatif.

Identifikasi budaya kreatif dilakukan dengan angket yang terdiri dari 14 pasang item pernyataan, total item pernyataan berjumlah 28 item. Angket dibagi menjadi dua kelompok, kelompok pernyataan A dan kelompok pernyataan B. Kelompok A berfungsi untuk mengidentifikasi faktor internal dan kelompok B untuk mengidentifikasi faktor eksternal. Dari hasil angket dapat diketahui faktor mana yang dominan mendorong budaya kreatif individu. Partisipan yang dilibatkan adalah 198 siswa SMA di Kota Bandar Lampung dengan latar belakang budaya yang heterogen. Analisis data pengujian instrumen menggunakan analisis faktor diolah dengan software analisis SPSS versi 17 dan model Rasch yang diolah dengan software analisis Winsteps versi 3.73.

\section{HASIL DAN PEMBAHASAN}

\section{Angket Budaya Kreatif}

Angket budaya kreatif diadaptasi dari angket pribadi kreatif yang dikembangkan oleh Eko Susanto et al (2016). Analisis Faktor menggunakan SPSS Versi 17, dilakukan untuk mengelompokkan item dengan kesamaan faktor.Model pertama dibuat angket dengan 22 pasang item dengan total item berjumlah 44 item pernyataan. Kemudian angket diujicobakan pada 198 siswa, hasil analisis faktor pertama diketahui nilai KMO .570 > .5dan Sig (p) 000 . Nilai ini mengisyaratkan bahwa layak dilakukan analisis faktor. Sebelum dilanjutkan pada analisis tahap kedua item yang memiliki nilai Anti-Image Correlation < .5 dikeluarkan dan tidak diikutkan pada analisis berikutnya. Hasil akhir terpilih 14 pasang item pernyataan dengan nilai Anti-Image Correlation > .5. Seluruh item terpilih (14 pasang item pernyataan) ini yang digunakan pada angket budaya kreatif.

Uji statistik kedua dilakukan untuk mengetahui validitas dan reliabilitas item. Alat analisis yang digunakan adalah model Rasch. Pemodelan Rasch merupakan alat analisis yang dapat menguji validitas (ketepatan) dan reliabilitas (keajegan) sebuah instrumen penelitian. Selain itu model Raschjuga memberikan informasi terkait kesesuaian person (responden) dan item secara simultan. Rasch memberi informasi tingkat validitas respon pada item berdasarkan nilai Outfit Mean Square (MNSQ) dengan nilai yang diterima 0,5< MNSQ $<1,5$. Outfit Z-Standard(ZSTD) kesesuaian nilai uji zdengan nilai yang 
diterima $-2,0<$ ZSTD $<+2,0$, dan Point Measure Correlation (Pt Mean Corr) dengan nilai yang diterima $0,4<\mathrm{Pt}$ Mean Corr $<0,85$. Untuk mengetahui pola jawaban responden dapat melihat nilai Infit MNSQ dan Outfit MNSQ dengan ekspektasi 1.0. Jika item pernyataan memenuhi syarat ini maka item instrumen layak digunakan. Hasil uji statistik semua item pernyataan memenuhi kriteria fit statistik dan dapat dikatakan valid dan layak digunakan sebagai instrumen penelitian.

Dari hasil perhitungan diketahui untuk person nilai Infit MNSQ adalah 1.00 dan Outfit MNSQ 1.01. Hal ini menunjukkan bahwa secara keseluruhan pola jawaban respon pada instrument adalah baik. Sedangkan untuk nilai Infit ZSTD dan Outfit ZSTD dengan ekspektasi .0 diketahui hasil perhitungan untuk person nilai Infit ZSTD adalah -.1 dan Outfit ZSTD -.0, nilai ini menunjukkan bahwa secara keseluruhan pola jawaban responden punya kesesuaian dengan model. Reliabilitas item pernyataan secara keseluruhan adalah .98 nilai ini masuk pada kategori sangat baik. Diketahui juga nilai Infit MNSQ adalah 1.00 dan Outfit MNSQ 1.01 dari nilai ekspektasi 1,0; sedangkan untuk ZSTDnilai Infit ZSTD adalah -.1 dan Outfit ZSTD .0 dari nilai ekspektasi .0. Kedua nilai ini menunjukkan bahwa keseluruhan item pernyataan adalah baik.

Item Diferensial (DIF); Bias item pada instrumen sering terjadi dengan adanya perbedaan atau keragaman responden bisa pada usia, jenis kelamin, domisili, ras, budaya dan lainnya.Item sebuah instrumen bisa saja lebih memihak pada responden dengan karakteristik tertentu saja. Analisis model Rasch menampilkan informasi ini pada differential item functioning (DIF). Dari hasil perhitungan diketahui seluruh item memiliki nilai Prob di atas 5\% $(0,05)$ (Sumintono \& Widhiarso, 2013).

\section{Interpretasi Hasil Analisis}

Berdasarkan analisis angket yang telah diisi oleh partisipan diketahui bahwa: (1) Ditinjau dari aspek internal dan eksternal budaya kreatif; Aspek eksternal 63\% lebih dominan ikut menentukan munculnya dorongan kreatif pada diri individu. Aspek eksternal individu seperti lingkungan, sosial, budaya, politik, dan keyakinan. Dalam referensi lain dikatakan bahwa budaya juga mempengaruhi bagaimana kreativitas disalurkan. Berbeda budaya, sosial, situasi politik dan sejarah dapat mendorong dan memupuk kreativitas dalam situasi tertentu melalui aktivitas manusia, tetapi dapat juga sebaliknya menghambat individu untuk kreatif. Sehingga, tergantung pada pengaturan 
budaya apakah memberikan ruang yang mendorong ekspresi kreatif atau tidak(Rudowicz, 2003).

(2) Ditinjau dari faktor determinan; berdasarkan hasil analisis faktor diketahui ada empat faktor yang mendorong budaya kreatif. Keempat faktor itu adalahaktivitas sosial, pertimbangan kognitif, pengambilan keputusan, dan orientasi individu. (3) Dilihat dari rata-rata sumbangan tiap faktor; faktor aktivitas sosial hampir sama dengan faktor orientasi individu dengan simpangan baku .493 dari sampel. Dua faktor lain yakni faktor pertimbangan kognitif dan faktor pengambilan keputusan. Dua faktor terakhir diduga sebagai faktor yang membedakan individu cenderung pada eksternal atau internal. Ketika faktor pertimbangan kognitif dan faktor pengambilan keputusan mendukung faktor aktifitas sosial, maka dorongan budaya kreatif cenderung eksternal. Artinya faktor lingkungan, sosial-budaya yang cenderung mendorong budaya kreatif individu tersebut, begitupun sebaliknya.

Uraian di atas membuktikan bahwa kreativitas ikut dipengaruhi oleh faktor budaya seseorang. Namun demikian pembuktian ini masih memiliki keterbatasan sampel dan referensi yang masih perlu diperkaya. Setidaknya kajian ini dapat memberikan bukti bahwa aspek eksternal mendominasi sebagai rujukan kreativitas seseorang. Saatnya untuk memulai budaya kreatif untuk dapat memfasilitasi perkembangan kreativitas individu. Budaya kreatif dapat dimulai dari lingkungan keluarga, sekolah, organisasi dan lingkungan masyarakat yang lebih luas.

\section{SIMPULAN}

Beberapa kesimpulan dari kajian ini terkait dengan budaya kreatif; Pertama, bahwa budaya memiliki peran dalam mendorong dan membentuk kreativitas seseorang. Kedua, kaitan antara budaya terhadap kreativitas memiliki dampak yang berbeda pada setiap orang. Terdapat kemungkinan dalam lingkungan yang sama tidak semua orang dapat menjadi kreatif. Ketiga, terdapat hubungan yang kompleks antara budaya dan kreativitas tidak sesederhana yang digambarkan dalam kajian ini. Keempat, interaksi antara pengaruh budaya dan kreativitas tidak hanya timbal balik tetapi juga melibatkan faktor sejarah, sosial dan aspek individu lainnya. Sehingga masih perlu dilakukan studi lebih lanjut untuk lebih memahami kaitan diantara keduanya. 


\section{REFERENSI}

Barron, F. (1988). Putting creativity to work. The nature of creativity, 76-98.

Cropley, A., \& Cropley, D. (2011). Creativity and Lawbreaking. Creativity Research Journal, 23(4), 313-320.

Cropley, A. J. (1992). More ways than one: Fostering creativity. New York: Ablex Publishing.

Csikszentmihalyi, M. (1988). Motivation and creativity: Toward a synthesis of structural and energistic approaches to cognition. New Ideas in psychology, 6(2), 159-176.

Csikszentmihalyi, M. (1999). 16 Implications of a Systems Perspective for the Study of Creativity. Handbook of creativity, 313.

Directorate-General for Education and Culture. (2009). The Impact of Culture on Creativity. Europe. http://doi.org/10.1093/tropej/fmw012.3.

Farver, J. A. M., Kim, Y. K., \& Lee-Shin, Y. (2000). Within cultural differences: Examining individual differences in Korean American and European American preschoolers' social pretend play. Journal of CrossCultural Psychology, 31(5), 583-602.

Gardner, H. (1989). The key in the slot: Creativity in a Chinese key. Journal of Aesthetic Education, 23(1), 141-158.

Khaleefa, O. H., Erdos, G., \& Ashria, I. H. (1997). Traditional Education and Creativity in an Afro-Arab. Islamic Culture: The Case of Sudan. The Journal of Creative Behavior, 31(3), 201-211.

Lubart, T. I., \& Sternberg, R. J. (1995). An investment approach to creativity: Theory and data. The creative cognition approach, 269-302.

Lubart, T. I., \& Sternberg, R. J. (1998). Creativity across Time and Place: life span and cross-cultural perspectives. High Ability Studies, 9(1), 59-74.

Ludwig, A. M. (1992). Culture and creativity. American Journal of Psychotherapy, 46(3), 454-469.

McLeod, J. (2013). An introduction to counselling. UK: McGraw-Hill Education.

Montuori, A., \& Purser, R. E. (1995). Deconstructing the lone genius myth: Toward a contextual view of creativity. Journal of Humanistic Psychology, 35(3), 69-112.

$\mathrm{Ng}$, A. K. (2003). A cultural model of creative and conforming behavior. Creativity Research Journal, 15(2-3), 223-233. 
Rudowicz, E. (2003). Creativity and Culture: A two way interaction. Scandinavian Journal of Educational Research, 47(October 2013), 273290.

Runco, M. A. (2004). Creativity. Annual Review of Psychology, 55(1), 657-687.

Runco, M. A., \& Albert, R. S. (Eds.). (1990). Theories of creativity (Vol. 990). Newbury Park, CA: Sage.

Sternberg, R. J., \& Lubart, T. I. (1991). An investment theory of creativity and its development. Human development, 34(1), 1-31.

Sternberg, R. J., \& Lubart, T. I. (1992). Creativity: Its nature and assessment. School Psychology International, 13(3), 243-253.

Sumintono, B., \& Widhiarso, W. (2013). Aplikasi Model Rasch untuk Penelitian Ilmu-ilmu sosial. Cimahi: Trim Komunikata Publishing House.

Simonton, D. K. (1988). 16 Creativity, leadership, and chance. The nature of creativity: Contemporary psychological perspectives, 386.

Stein, M. I. (1953). Creativity and culture. The journal of psychology, 36(2), 311-322.

Susanto, E., Novitasari, Y., Ilfiandra, \& Yusuf, S. (2016). Creative personality inventory. Available: www.researchgate.net. 